\title{
The Relationship between Recovery Experience and Life Satisfaction: The Mediating Role of Work-Family Enrichment
}

\author{
Yaran Zhou \\ Jinan University, Guangzhou, China \\ Email: zhouyaran1997@163.com
}

How to cite this paper: Zhou, Y. R. (2021). The Relationship between Recovery Experience and Life Satisfaction: The Mediating Role of Work-Family Enrichment. Psychology, 12, 554-566.

https://doi.org/10.4236/psych.2021.124034

Received: March 7, 2021

Accepted: April 16, 2021

Published: April 19, 2021

Copyright (๑) 2021 by author(s) and Scientific Research Publishing Inc. This work is licensed under the Creative Commons Attribution International License (CC BY 4.0).

http://creativecommons.org/licenses/by/4.0/

\section{(c) (i) Open Access}

\begin{abstract}
Objectives: To analyze the factors that affect the life satisfaction of employees and to explore the mechanism of recovery experience affecting life satisfaction. Methods: The study uses the questionnaire survey to conduct convenient sampling surveys. Sonnentag and Fritz's Recovery Experience Scale, Work-Family Gain Scale developed by Carlson et al. and Life Satisfaction Scale developed by Diener et al. were used to survey 500 employees in $\mathrm{Wu}-$ han. Results: Regression analysis revealed that recovery experience positively influenced life satisfaction. Direct effect of recovery experience on life satisfaction is $0.646(p<0.01)$. Mediation analysis found that recovery experience influenced life satisfaction through work-family enrichment. Indirect effect of recovery experience on life satisfaction is $0.213(p<0.001)$. Conclusions: 1$)$ Employees' recovery experience positively predicted life satisfaction; 2) Work-family enrichment mediated the relationship between recovery experience and life satisfaction. Our results show both limitations and intriguing directions for future research.
\end{abstract}

\section{Keywords}

Recovery Experience, Life Satisfaction, Work-Family Enrichment, Conservation of Resource Theory

\section{Introduction}

With the rapid development of economy, social competition is becoming more and more intense, and the pace of work is greatly accelerated. It is evident that employees are feeling a gradually increasing workload. Under the influence of modern mobile communication technology, employees are forced to deal with 
matters even during off-hours, and the line between work life and family life is increasingly blurred. Work tasks and stress are not only present at the workplace and during working hours, but also have a direct impact on employees' family life. The stress caused by work-family conflict plagues everyone in the workplace. Chronic stress poses a threat to employees' mental health and leads to various psychological problems that negatively affect work performance and quality of life (Chen, Petrick, \& Shahvali, 2014). Therefore, it is important to explore ways to help employees recover from work-related stress. Recovery experience as an important way to help people relieve the stress of work and enjoy life, has received considerable attention from scholars (Barber, Conlin, \& Santuzzi, 2019).

In the field of physiology, recovery is considered as a process of physical and psychophysiological indicators changing in a better direction (Linden, Earle, Gerin, \& Christenfeld, 1997). Recovery is summarized as a process opposite to the stress process, which refers to the decrease of the negative state (e.g., fatigue) and the increase of the positive state (e.g., vitality). When the stressor disappears, the relevant functional systems of the individuals return to the pre-stress state (Meijman, Mulder, Drenth, \& Thierry, 1998). When the research of recovery goes from the physiological to the psychological, researchers propose the "recovery experience". Recovery experience refers to the psychological process of employees recovering from occupational stress, which mainly includes four dimensions: relaxation experience, psychological detachment, mastery experience and control experience ( $\mathrm{Wu}, \mathrm{Liu}, \& \mathrm{Xie}, 2012)$. Contrary to the process of building stress, when an individual experiences a recovery experience, he will recover at the physical, cognitive and emotional levels to reduce psychological stress (Sonnentag \& Fritz, 2007). Recovery experience can be achieved through specific recovery activities: activities such as sports, watching movies, listening to music, reading, outing and other activities can bring relaxation experience; leaving the work unit, stopping all jobs and cutting off all work connections can bring psychological disengagement; after getting off work, one can control time and not be controlled by work, which can bring control experience; learning new skills, cultivating new hobbies, exploring new fields and meeting new challenges can bring mastering experience. Psychological disengagement, relaxation experience, mastering experience and control experience are the four dimensions of recovery experience channels that help employees regain their energy from the energy exhaustion after experiencing stress, which devote themselves to work in a positive state ( $\mathrm{Wu}, \mathrm{Liu}, \& \mathrm{Xie}, 2012)$.

These recovery activities usually occur during non-working hours. On the one hand, they occur during short non-working hours, such as weekday evenings or weekends. On the other hand, they occur during long non-working hours, such as long vacations (Etzion, 2003). Compared with short weekends, long-distance leisure travel provides individuals with more opportunities to obtain recovery experience. Based on the bottom-up spillover theory (Diener \& Emmons, 1984), a better recovery experience helps to improve the individual's life satisfaction (Chen, Petrick, \& Shahvali, 2014). Although the activities of the recovery expe- 
rience are diverse, and the recovery process can occur at different times and environmental settings, the underlying psychological process to achieve recovery is roughly the same (van Veldhoven \& Sluiter, 2009; Sonnentag \& Fritz, 2007). The recovery experience has many direct and indirect effects on people in the workplace, which is beneficial to the physical and mental health of individuals. It can help people get rid of the tension in work and feel relaxed, so that employees can recover the resources consumed in work stress. At the same time, recovery experience can also affect the work and life of individuals. For example, recovery experience can positively predict individuals' job performance, work satisfaction and life satisfaction (Wu, Liu, \& Xie, 2012). In general, recovery experience is related to positive outcomes and has the characteristics of exploitability. We can improve the quantity and quality of individual recovery experience through effective ways.

According to the conceptual model of subjective well-being by Newman et al. (2014), life satisfaction is the key well-being result of the recovery experience. Life satisfaction refers to a person's comprehensive assessment of their living environment, including positive or negative emotional experiences (Diener, Suh, Lucas, \& Smith, 1999). Life satisfaction is an individual's overall evaluation of life, and the object of evaluation is not limited to a certain area of life (Veenhoven, 1996). The subjective well-being conceptual model assumes that the recovery experience from leisure activities is the key to improving life satisfaction. Specifically, this model views the experience of recovery as a psychological mechanism that links one's leisure activities with life satisfaction (Park \& Fritz, 2015). Leisure activities can help employees temporarily detach themselves from work demands and stressors so as to recover resources lost in work (Meijman, Mulder, Drenth, \& Thierry, 1998).

Resource conservation theory assumes that individuals make efforts to acquire and retain external resources (such as financial assets) and internal resources (such as personal energy and positive emotions) to offset resource losses and prevent future losses, which is crucial for dealing with people's survival needs (Hobfoll, 1989). The theory affirms the value of these resources as well as their exploitable value.

If the resource previously occupied by the individual is consumed, or if the individual has worked hard but fails to regain resources from the outside world, then the individual will have a great sense of frustration and feel a continuous loss of psychological energy. Stress leads to internal resource depletion, and employees have to either acquire new resources (such as energy, self-efficacy, and positive emotions) or recover lost resources. When individuals regain more reliable resources, they will be more inclined to look at their lives in a favorable way (Hobfoll, 2002). When people can freely control their time, determine what they want to do and learn new things, etc., they can obtain new internal resources (Hobfoll, 1989).

Quality recovery experience helps individuals make up for the resources consumed in work successfully, and they will feel more life satisfaction; on the con- 
trary, if the individual has been in a highly stressful work and life situation, it will make people energy exhaustion and less life satisfaction. Therefore, researches suggest that there is a positive correlation between recovery experience and life satisfaction (Chen, Petrick, \& Shahvali, 2016). A higher level of recovery experience will lead to greater life satisfaction, while a lower level of recovery experience will lead to lower life satisfaction. Based on the above literature, this research hypothesized the following:

$\mathrm{H} 1$ : Recovery experience will exert a positive influence on life satisfaction.

The study further explores the internal mechanism of the impact of recovery experience on life satisfaction. Multi-level analysis shows that more work pressure and less recovery experience at a daily level can predict work-family conflict and fatigue (Newman, Tay, \& Diener, 2014), while recovery experience gained after a short break at work can predict work-family gain and vitality (Sanz-Vergel, Demerouti, Moreno-Jiménez, \& Mayo, 2010). Although family lives and work may interfere with one another, resources generated in either domain have also been shown to enhance the quality of life in the other (Liu, Siu, \& Shi, 2010). This positive aspect of the work-family interface is referred to work-family enrichment (Brough, Hassan, \& O’Driscoll, 2014).

Work-family enrichment includes two aspects: on the one hand, it refers to the work-to-family enrichment. For example, the material resources obtained from work can improve subjective well-being and life satisfaction. On the other hand, it refers to family-to-work enrichment. For example, family provides solid support for individuals and makes individuals devote themselves to work to improve work performance (Powell \& Greenhaus, 2006). Positive emotional expression in work and family life is a powerful strategy to reduce work-family conflict and enhance work-family enrichment (Sanz-Vergel, Demerouti, Moreno-Jiménez, \& Mayo, 2010). Recovery experience brings more positive emotions and subjective well-being to individuals. Therefore, recovery experience positively affects work-family enrichment. In addition, good recovery experience provides individuals sufficient time and space to balance work and life. The positive interaction between work and life further helps individuals to achieve work-family enrichment and obtain more resources needed for healthy development of body and mind (Chan, Kalliath, Brough, Siu, O’Driscoll, \& Timms, 2016).

Indicators such as work-family enrichment, work-family balance, and work-family conflict reflect an individual's overall assessment of work and family life, which directly affect life satisfaction (Chan, Kalliath, Brough, Siu, O'Driscoll, \& Timms, 2016). At the same time, work-family gain also directly affects individuals' work performance, self-efficacy, physical health and subjective well-being (McNall, Nicklin, \& Masuda, 2010; Carlson, Ferguson, Kacmar, Grzywacz, \& Whitten, 2011; Allis \& O’Driscoll, 2008). According to resource conservation theory, the unilateral outflow of individual survival resources will make it difficult to support people's life, and damage mental health (Wright \& Cropanzano, 1998). Recovery experience and work-family enrichment bring about the acquisition and compensation of individual survival resources. Abun- 
dant resources make individual more inclined to show a positive attitude towards lives, thereby enhancing life satisfaction. Based on the above literature, this research hypothesizes the following:

H2: Work-family enrichment plays a mediating role between employees' recovery experience and life satisfaction.

To sum up, this research is based on the fast-paced modern era background, with employees as the object, from the perspective of recovery experience, exploring 1) the relationship between recovery experience and life satisfaction; 2) the mediating mechanism of work-family enrichment between recovery experience and life satisfaction.

\section{Methods}

The study will use the method of questionnaire survey to distribute 500 questionnaires in Wuhan. First, we sort out the invalid questionnaires in the returned questionnaires: removing 32 questionnaires in which the number of missed questions exceeds two-thirds of the total questionnaire and 45 questionnaires with the same option selected in the entire questionnaire, and finally we get 423 valid questionnaires. The calculated recovery rate is $84.60 \%$. In the effective sample, there are 207 men, accounting for $48.9 \%$, and 216 women, accounting for $51.1 \%$. The number of married people is 429 , accounting for $99.3 \%$, and the number of unmarried people is 3 , accounting for $0.7 \% .88 .6 \%$ of people work around 30 - 60 hours a week. In terms of education level, $45.4 \%$ of people have a bachelor degree or above (Table 1 ).

Table 1. The sample profile $(n=423)$.

\begin{tabular}{|c|c|c|c|}
\hline Variables & & $\mathrm{N}$ & $\%$ \\
\hline \multirow{2}{*}{ Gender } & Female & 207 & 48.9 \\
\hline & Male & 216 & 51.1 \\
\hline \multirow{3}{*}{ Age } & $\leq 30$ & 89 & 21 \\
\hline & $31-35$ & 67 & 15.9 \\
\hline & $\geq 35$ & 267 & 63.1 \\
\hline \multirow{2}{*}{ Marriage } & Married & 420 & 99.3 \\
\hline & Unmarried & 3 & 0.7 \\
\hline \multirow{3}{*}{ Working hours per week } & $0-30$ & 18 & 4.3 \\
\hline & $30-60$ & 375 & 88.6 \\
\hline & $\geq 60$ & 30 & 7.1 \\
\hline \multirow{5}{*}{ Education } & Junior high school & 52 & 12.3 \\
\hline & High school & 75 & 17.7 \\
\hline & College & 104 & 24.6 \\
\hline & Graduate school & 160 & 37.8 \\
\hline & Master degree and above & 32 & 7.6 \\
\hline
\end{tabular}




\subsection{Recovery Experience Scale}

The Recovery Experience Scale used in the study was compiled by Sonnentag and Fritz (2007), with a total of 16 topics, such as "I can forget about work during non-working hours." The scale uses Likert five points, in which "1" means "completely disagree" and " 5 " means "completely agree". Those with high scores get high-level recovery experience, and those with low scores get low-level recovery experience. The scale was translated by two Ph.Ds. Then it was tested and evaluated by distributing the questionnaires. The reliability and validity are well. The alpha coefficient of the measurement table in this study is 0.839 .

\subsection{Work-Family Enrichment Scale}

Carlson et al. (2011) compiled the Work-Family Enrichment Scale in 2006. The scale has 4 topics, including "The work I do helps me deal with personal and practical problems at home", "The work I do can help me become a more interesting person at home", "Smooth work during the day allows me to better play the role of a partner at home", and "The skills I use at work are equally effective when dealing with family affairs". We use the Likert five-point scale, and "1 - 5" respectively stand for "completely inconsistent-completely consistent".

The higher the employee's score, the higher level of work-family gain he gets. The lower the score, the lower level of work-family gain he gets. The reliability and validity of the scale have been verified by Chinese scholars' actual questionnaires. The analysis results showed that the coefficient of $\alpha$ of the scale is 0.773 .

\subsection{Life Satisfaction Scale}

The Life Satisfaction Scale developed by Diener et al. (1985) has five items, such as "Most aspects of my life are close to my ideal state". Likert seven-point scoring scale was adopted. "1" represents "completely inconsistent", "2" represents "relatively inconsistent”, "3" represents "somewhat inconsistent", “4” represents "unclear", "5" represents "somewhat consistent", “6" represents "fairly consistent" and " 7 " represents "completely consistent". The higher score presents more life satisfaction. The $\alpha$ coefficient of the scale was 0.896 in this measurement.

\subsection{Control Variables}

According to the results of collecting data, it is found that individuals with different basic situations have more obvious differences in life satisfaction. We are thinking about whether basic demographic variables can influence the individual's recovery experience. Therefore, this study selects gender and marriage as control variables. In the measurement, gender is expressed as male (1) female (0). Marriage is expressed as married (1) and unmarried (2).

We used the face-to-face questionnaire survey data collection method. Before the test, participants must fully understand the content of the questionnaire and the answering method. The questionnaires are all anonymous, informing the 
subjects that they do not have to worry about information leakage. We use manual input to sort out the recovered questionnaires and data. Then we use SPSS 21.0 for descriptive statistical analysis, reliability analysis, correlation analysis, and regression analysis. Finally we use model 4 in the plug-in Process 21.0 for mediating effect analysis.

\section{Results}

\subsection{Common Method Bias Test}

The study used SPSS 21.0 software to place the variables of recovery experience, work-family enrichment, and recovery experience all into exploratory factor analysis to test the results of the unrotated factor analysis. The results indicated that the first common factor was explained by only $21.51 \%$ and that a larger number of factors were analysed. It can be inferred that common method bias did not have much impact on the results of this study.

\subsection{Descriptive Analysis and Correlation Analysis}

The following Table 2 lists the descriptive statistics and related analysis results of each variable. The analysis results show that the employees' recovery experience level $(\mathrm{M}=3.534, \mathrm{SD}=0.561)$ and the perceived life satisfaction is higher $(\mathrm{M}=4.399, \mathrm{SD}=1.359)$. Correlation analysis results show that there is a significantly positive correlation between recovery experience and life satisfaction $(\mathrm{r}=$ $0.356, p<0.01)$. Recovery experience can positively predict life satisfaction. When one gets a higher level of recovery experience, he or she gains more life satisfaction. The hypothesis one is verified. The employee's recovery experience and work-family enrichment showed a significant positive correlation $(\mathrm{r}=0.313$, $p<0.01$ ), and work-family enrichment and life satisfaction showed a significant positive correlation ( $\mathrm{r}=0.365, p<0.01)$. This is the supporting basis to further examine the mediating effect of work-family enrichment.

\subsection{Mediating Effect Test}

This study uses the SPSS-based intermediary analysis program plug-in Process macro program developed by Hayes, and uses model 4 to analyze the mediating

Table 2. The mean, standard deviation of each variable and the correlation coefficient between variables $(n=423)$.

\begin{tabular}{ccccccc}
\hline Variables & $M$ & $S D$ & 1 & 2 & 3 & 4 \\
\hline Recovery experience & 3.534 & 0.561 & & & & \\
Work-family enrichment & 3.187 & 0.821 & $0.313^{* *}$ & & & \\
Life satisfaction & 4.399 & 1.359 & $0.356^{* *}$ & $0.365^{* *}$ & & \\
Gender & 0.610 & 0.601 & -0.032 & -0.015 & -0.032 & \\
Marriage & 1.010 & 0.084 & -0.021 & -0.062 & -0.017 & 0.055 \\
\hline
\end{tabular}

${ }^{* *} p<0.01$ 
effect of work-family enrichment between recovery experience and life satisfaction. There are three main advantages to using the Process plug-in. Firstly, Only one step is needed to test the mediation effect, and the mediation effect test is more convenient and the results are more comprehensive. Secondly, Bootstrap of the mediation effect no longer needs special settings, and the Sobel test of the mediation effect no longer needs to be calculated manually, which can be processed automatically. Finally, when there are control variables, the Process plug-in can also test mediation effect, making it more convenient to deal with multivariate mediation.

We take recovery experience as an independent variable, work-family gain as an intermediary variable, and life satisfaction as a dependent variable. We use demographic variables as a control variable and use model 4 in the SPSS macro Process for analysis. The analysis results are as follows: Table 3 and Table 4. In the case of controlling for demographic variables such as gender and marriage status, the regression coefficient of the antecedent outcome variable recovery experience on the work-family gain is $0.456(p<0.01)$; the regression coefficient of the mediating variable work-family enrichment on the outcome variable recovery experience is $0.467(p<0.01)$. After controlling the control variables, the regression coefficient of the recovery experience on life satisfaction is $0.646(p<$ $0.01)$, and the direct effect is significant; the indirect effect is $0.213(p<0.01)$, and the indirect effect is significant.

In summary, the employee's work-family enrichment plays a mediating role between the recovery experience and life satisfaction. Employee's recovery experience can affect life satisfaction by affecting the work-family enrichment.

Table 3. Regression analysis result.

\begin{tabular}{|c|c|c|c|c|}
\hline \multirow{2}{*}{ Variables } & \multicolumn{2}{|c|}{ Work-family enrichment } & \multicolumn{2}{|c|}{ life satisfaction } \\
\hline & $\beta$ & $S E$ & $\beta$ & $S E$ \\
\hline Gender & -0.003 & 0.063 & -0.045 & 0.099 \\
\hline Marriage & -0.543 & 0.454 & 0.124 & 0.712 \\
\hline Recovery experience & $0.456^{* *}$ & 0.063 & $0.646^{* *}$ & 0.112 \\
\hline Work-family enrichment & & & $0.467^{\star *}$ & 0.076 \\
\hline$F$ & \multicolumn{2}{|c|}{$15.67^{\star *}$} & \multicolumn{2}{|c|}{$25.875^{\star *}$} \\
\hline$R^{2}$ & \multicolumn{2}{|c|}{0.101} & \multicolumn{2}{|c|}{0.199} \\
\hline
\end{tabular}

${ }^{* *} p<0.01$.

Table 4. Mediating effect test result.

\begin{tabular}{|c|c|c|c|c|c|}
\hline \multicolumn{3}{|c|}{$\mathrm{X} \rightarrow \mathrm{Y}$ Indirect effect } & \multicolumn{3}{|c|}{$X \rightarrow$ Y Direct effect } \\
\hline$\beta$ & $S E$ & Boot 95\%CI & $\beta$ & $S E$ & Boot $95 \%$ CI \\
\hline 0.213 & 0.048 & {$[0.1264,0.3137]$} & 0.646 & 0.112 & {$[0.4268,0.8659]$} \\
\hline
\end{tabular}

Note: X means Independent variable; Y means dependent variable. 


\section{Discussion}

The study takes employees as the research object, and has certain theoretical and practical significance for the research in the field of organizational behavior. With abundant material resources, more and more people are beginning to pay attention to mental health and subjective well-being. Recovery experience as a way to relieve stress and obtain a good life experience has been paid more and more attention by scholars and the public. This research explores the impact of recovery experience on life satisfaction, and proves the mediating role of work-family gain between the two variables through empirical analysis, which enriches the theoretical research on recovery experience. In addition, the object of this study is employees of enterprises or institutions. The results of the study show that recovery experience can positively predict life satisfaction. A good recovery experience leads to more life satisfaction. Recovery experience will bring better work-family enrichment, reduce work-family conflicts, and improve people's life satisfaction. This suggests that enterprises can provide employees with professional psychological disengagement training and relaxation counseling, so that individuals can get better recovery experience. In this way, individuals will enable to obtain resources that help improve the quality of life and work, so as to enhance professional well-being and life satisfaction.

\subsection{The Relationship between Recovery Experience and Life Satisfaction}

In the context of the rapid development of modern society, this research pays attention to the factors that affect people's life satisfaction. The study found that there is a positive correlation between employees' recovery experience and life satisfaction. Recovery experience can positively predict life satisfaction. Recovery experience can directly affect life satisfaction, or indirectly affect life satisfaction through intermediary variables. A higher level of recovery experience may bring a higher level of life satisfaction. Obtaining recovery experience through leisure and entertainment activities during non-working hours is one of the important ways to improve life satisfaction.

According to the conservation of resources theory, when individuals make up for the resources consumed in work and obtain an experience of relaxation, they will view life and experience in a more favorable way. Therefore, they are more inclined to feel satisfied with life. In contrast, if the individual has low level of recovery experience, and has been in a state of stress, it will be more difficult to produce a high level of life satisfaction.

The relationship between the two variables gives us great inspirations. We can improve recovery experience by learning and mastering efficient methods, and help improve life satisfaction. Companies and organizations can also make use of professional recovery experience training, helping employees master the way to obtain a high-level recovery experience, which may enhance life satisfaction and organizational performance. 


\subsection{The Mediating Role of Work-Family Enrichment}

The findings confirm the hypothesis that work-family enrichment plays a mediating role between the recovery experience and life satisfaction. The direct effect of recovery experience on life satisfaction is $0.646(p<0.01)$, and the indirect effect of recovery experience on life satisfaction is $0.213(p<0.001)$, which indicates that the recovery experience not only has a direct effect on life satisfaction, it also indirectly affects life satisfaction through part of the mediating effect of work-family enrichment. The work-family resource theory explains the interactive process between resources and needs in the work and family fields, and assumes that situational resources are the starting point of the work-family enrichment process (Chen, Petrick, \& Shahvali, 2016). Work-family enrichment is that an individual gains resources in work, which can help improve the quality of family life. It is an important intermediary mechanism that explains the impact of work resources on the family field. Recovery experience and work-family enrichment are important energy sources. Multi-level analysis shows that work pressure at a daily level and recovery experience gained after a short break at work can predict work-family conflict and work-family gain respectively. And work-family enrichment can supplement individual resources and produce a higher level of life satisfaction. This study shows that work-family enrichment plays a mediating role between recovery experience and life satisfaction. Recovery experience can directly affect life satisfaction or indirectly affect life satisfaction through work-family enrichment.

Therefore, improving people's life satisfaction can start from these two aspects. The organization can organize training, helping employees to have a more comprehensive understanding of the recovery experience, and teach effective means to obtain the recovery experience, so as to help employees in non-work time to get a better recovery experience and organizational efficiency. Moreover, the organization should arrange working hours reasonably to reduce work-family conflicts and minimize the unnecessary consumption of mental energy for employees. Individuals who exert subjective initiative in a good external environment can greatly enhance life satisfaction.

\subsection{Limitation}

The study explores the relationship between recovery experience and life satisfaction and the mediating role of work-family enrichment under the unique cultural background of China. The research has theoretical and practical significances. However, the study still has the following two limitations.

First, this study adopted the cross-sectional method, which could not infer the causal relationship. Although the results of the study were supported by relevant theories, it was difficult to carry out a longitudinal study due to the limited time, so it was impossible to make a comparison through the longitudinal study. Future studies can further explore the relationship between recovery experience and life satisfaction through comparison of longitudinal studies. 
Secondly, this research used the questionnaire distribution method to collect the data. The subjects participated in the study through self-reporting, so they are prone to homology deviation. In addition, it is greatly influenced by subjective factors, and the collected data lacks certain objectivity. In future studies, we can enrich the data sources and collection methods of data to avoid homologous bias and subjective bias.

\section{Conclusion}

Conclusion 1: Recovery experience can positively predict employees' life satisfaction. The higher the employee's recovery experience level, the higher the life satisfaction.

Conclusion 2: The work-family enrichment of employees plays an intermediary role in the recovery experience and life satisfaction. That is, the recovery experience is positively related to work-family enrichment, which in turn has a positive impact on life satisfaction.

\section{Conflicts of Interest}

The author declares no conflicts of interest regarding the publication of this paper.

\section{References}

Allis, P., \& O'Driscoll, M. (2008). Positive Effects of Nonwork-to-Work Facilitation on Well-Being in Work, Family and Personal Domains. Journal of Managerial Psychology, 23, 273-291. https://doi.org/10.1108/02683940810861383

Barber, L. K., Conlin, A. L., \& Santuzzi, A. M. (2019). Workplace Telepressure and Work-Life Balance Outcomes: The Role of Work Recovery Experiences. Stress and Health, 35, 350-362. https://doi.org/10.1002/smi.2864

Brough, P., Hassan, Z., \& O’Driscoll, M. (2014). Work-Life Enrichment. In M. Dollard, A. Shimazu, R. Bin Nordin, P. Brough, \& M. Tuckey (Eds.), Psychosocial Factors at Work in the Asia Pacific (pp. 323-336). Dordrecht: Springer. https://doi.org/10.1007/978-94-017-8975-2 17

Carlson, D. S., Ferguson, M., Kacmar, K. M., Grzywacz, J. G., \& Whitten, D. (2011). Pay It Forward: The Positive Crossover Effects of Supervisor Work-Family Enrichment. Journal of Management, 37, 770-789. https://doi.org/10.1177/0149206310363613

Chan, X. W., Kalliath, T., Brough, P., Siu, O. L., O’Driscoll, M. P., \& Timms, C. (2016). Work-Family Enrichment and Satisfaction: The Mediating Role of Self-Efficacy and Work-Life Balance. The International Journal of Human Resource Management, 27, 1755-1776. https://doi.org/10.1080/09585192.2015.1075574

Chen, C. C., Petrick, J. F., \& Shahvali, M. (2014). Tourism Experiences as a Stress Reliever: Examining the Effects of Tourism Recovery Experiences on Life Satisfaction. Journal of Travel Research, 55, 150-160. https://doi.org/10.1177/0047287514546223

Diener, E., \& Emmons, R. A. (1984). The Independence of Positive and Negative Affect. Journal of Personality and Social Psychology, 47, 1105-1117. https://doi.org/10.1037/0022-3514.47.5.1105

Diener, E., Suh, E. M., Lucas, R. E., \& Smith, H. L. (1999). Subjective Well-Being: Three 
Decades of Progress. Psychological Bulletin, 125, 276-302.

https://doi.org/10.1037/0033-2909.125.2.276

Etzion, D. (2003). Annual Vacation: Duration of Relief from Job Stressors and Burnout. Anxiety, Stress, and Coping, 16, 213-226. https://doi.org/10.1080/10615806.2003.10382974

Hobfoll, S. E. (1989). Conservation of Resources: A New Attempt at Conceptualizing Stress. American Psychologist, 44, 513-524. https://doi.org/10.1037/0003-066X.44.3.513

Hobfoll, S. E. (2002). Social and Psychological Resources and Adaptation. Review of General Psychology, 6, 307-324. https://doi.org/10.1037/1089-2680.6.4.307

Linden, W. L. E. T., Earle, T. L., Gerin, W., \& Christenfeld, N. (1997). Physiological Stress Reactivity and Recovery: Conceptual Siblings Separated at Birth? Journal of Psychosomatic Research, 42, 117-135. https://doi.org/10.1016/S0022-3999(96)00240-1

Liu, J., Siu, O. L., \& Shi, K. (2010). Transformational Leadership and Employee Well-Being: The Mediating Role of Trust in the Leader and Self-Efficacy. Applied Psychology, 59, 454-479. https://doi.org/10.1111/j.1464-0597.2009.00407.x

McNall, L. A., Nicklin, J. M., \& Masuda, A. D. (2010). A Meta-Analytic Review of the Consequences Associated with Work-Family Enrichment. Journal of Business and Psychology, 25, 381-396. https://doi.org/10.1007/s10869-009-9141-1

Meijman, T. F., Mulder, G., Drenth, P., \& Thierry, H. (1998). Psychological Aspects of Workload. In P. J. D. Drenth, H. Thierry, \& C. J. de Wolff (Eds.), Handbook of Work and Organizational Psychology (Vol. 2, pp. 5-34). Hove: Psychology Press.

Newman, D. B., Tay, L., \& Diener, E. (2014). Leisure and Subjective Well-Being: A Model of Psychological Mechanisms as Mediating Factors. Journal of Happiness Studies, 15, 555-578. https://doi.org/10.1007/s10902-013-9435-x

Park, Y., \& Fritz, C. (2015). Spousal Recovery Support, Recovery Experiences, and Life Satisfaction Crossover among Dual-Earner Couples. Journal of Applied Psychology, 100, 557-566. https://doi.org/10.1037/a0037894

Powell, G. N., \& Greenhaus, J. H. (2006). Is the Opposite of Positive Negative? Untangling the Complex Relationship between Work-Family Enrichment and Conflict. Career Development International, 11, 650-659. https://doi.org/10.1108/13620430610713508

Sanz-Vergel, A. I., Demerouti, E., Moreno-Jiménez, B., \& Mayo, M. (2010). Work-Family Balance and Energy: A Day-Level Study on Recovery Conditions. Journal of Vocational Behavior, 76, 118-130. https://doi.org/10.1016/j.jvb.2009.07.001

Sonnentag, S., \& Fritz, C. (2007). The Recovery Experience Questionnaire: Development and Validation of a Measure for Assessing Recuperation and Unwinding from Work. Journal of Occupational Health Psychology, 12, 204-221. https://doi.org/10.1037/1076-8998.12.3.204

Van Veldhoven, M. J., \& Sluiter, J. K. (2009). Work-Related Recovery Opportunities: Testing Scale Properties and Validity in Relation to Health. International Archives of Occupational and Environmental Health, 82, 1065-1075. https://doi.org/10.1007/s00420-009-0411-Z

Veenhoven, R., Saris, W. E., Scherpenzeel, A. C., \& Bunting, B. (1996). A Comparative Study of Satisfaction with Life in Europe (pp. 11-48.). Budapest: Eotvos University Press.

Wright, T. A., \& Cropanzano, R. (1998). Emotional Exhaustion as a Predictor of Job Performance and Voluntary Turnover. Journal of Applied Psychology, 83, 486-493. 
https://doi.org/10.1037/0021-9010.83.3.486

Wu, W. J., Liu, Y., \& Xie, X.X. (2012). Review and Prospects of Foreign Restoration Experience Research. Foreign Economics and Management, 34, 44-51. 